\title{
اتجاهات طلاب الصف الحادي عشر وأولياء أمورهم نحو استخدام التعليم عن بعد في محافظة الظاهرة في ظل جائحة كورونا
}

\author{
سيف بن ناصر بن لسيف العزري \\ أستاذ مساعد- كلية العلوم والآداب- جاهعة نزوى- سلطنة عُمان \\ saifnasser@unizwa.edu.om
}


اتجاهات طلاب الصـف الحادي عشروأولياء أمورهم نحو استخدام التعليم عن بعد في محافظة الظاهرة في ظل جائحة كورونا

\author{
سيف بن ناصرب بن سيف العزري
}

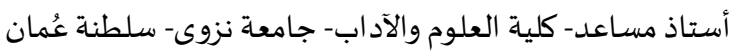

saifnasser@unizwa.edu.om

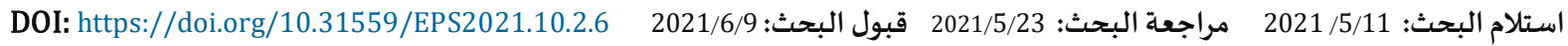

هدفت هذه الدراسـة الكشف عن اتجاهات توظيف التعليم عن بعد اعتماداً على وجهة نظر عينة من طلاب الصف الحادي عشر وآبائهم

في محافظة الظاهرة في سلطنة عمان من خلال استبانتين تم تطبيقهما على عينة من طلاب الصف الحادي عشر الذين يمثلون التعليم ما بعد العام إضافة إلى وجهة نظر آبائهم. وقد بلغت عينة الدراسة (104) طالباً وولي أمر مقسمين إلى (52) من الطلاب ومعههم (52) هم أولياء أمورهم

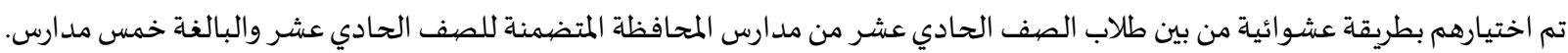

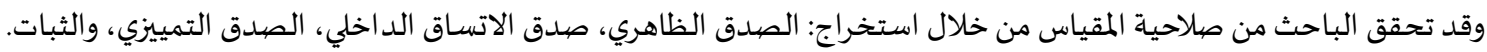

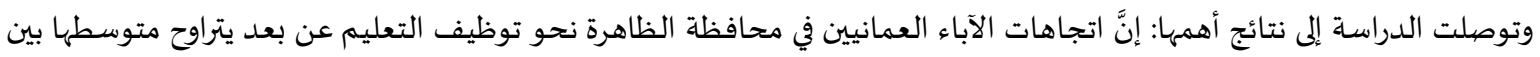
(2.76)- (4.18)؛ مما يشير إلى وقوعه في الفئتين المتوسطة والكبيرة، اتجاهات أبنائهم نحو التعليم عن بعد قد تراوح متوسطها بين (2.15) و

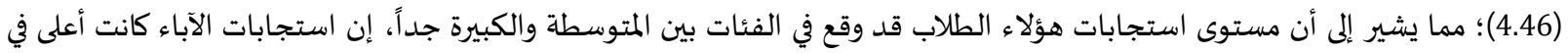
متوسطها الحسابي من متوسط استجابات أبنائهم في (12) فقرات من فقرات المقياس من بين (15) فقرة، هناك تقارب واتفاق بين آراء الطلاب

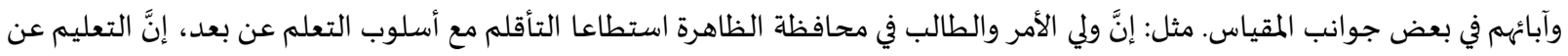
بعد من وجهاة نظر الآباء وأبنائهم قد أسهم بصورة مباشرة في فهم دروس المنهج بصورة متساوية مع أسلوب التعليم المباشر، كما كانت وجها نظرهم متفقة في أنّ الشبكة وخدمة الإنترنت هي في مقدمة التحدياتهات التي واجهت الأسرة العمانية. وقدمت الدراسة في النهاية مجموعة من التوصيات ذات العلاقة بنتائجها.

الكلمات المفتاحية: التعليم عن بعد؛ طلاب التعليم الأسـاسي؛ سلطنة عمان.

لم يعد التعليم الإلكتروني مفهوماً من مفاهيم الترف الفكري في العمل التربوي، كما لم يعد كذلك قاصراً على استخدام التكنولوجيا الحديثة من

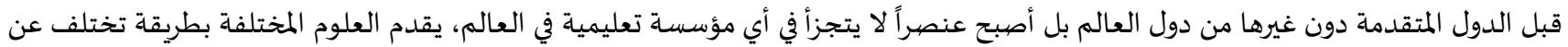
التقليدية، ومقدماً حلولاً للمشكلات التي تعاني منها بعض الدول دولي في إيصال العلم والمعرفة لكافة شرائح المجتمع. ومفهوم التعليم الإلكتروني كما يشير شلوسر وشيمونسن فياء تنوع واختلاف في صياغة المفهوم إلا أن تلك المفاهيم تشترك فيما فئها بينها في تمحورها حول أنها شكل من أشكال التعليم عن بعد عن طريق استخدام آليات الاتصال الحديثة كالحاسب الآلي، والشبكات، والوسائط المتعددة، وبوابات الإنترنت؛

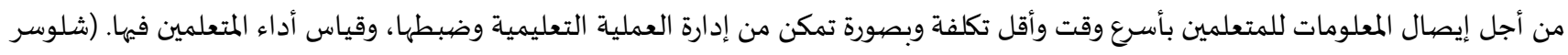
وشيمونسن، 2015) 
وبالمضهمون نفسه يعرف الخفاجي (2015، 7-5) التعليم عن بعد على أنه أسلوب من أساليب التعليم الإلكتروني يرتكز على مبدأ التعليم الذاتي

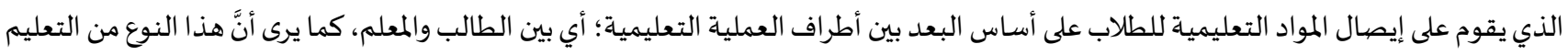

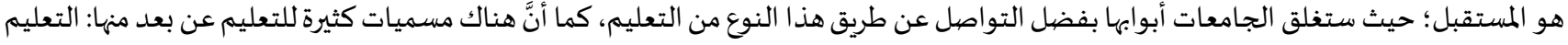

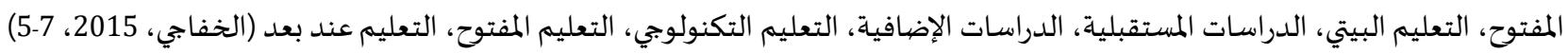

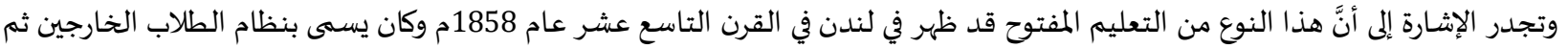

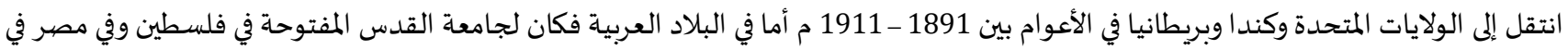

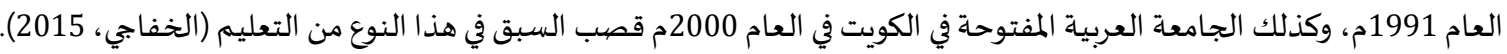

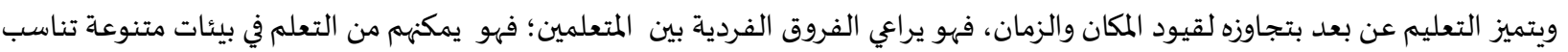

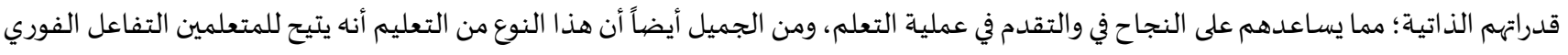

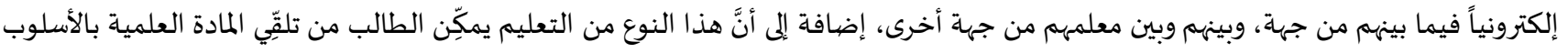

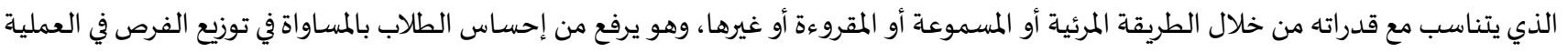

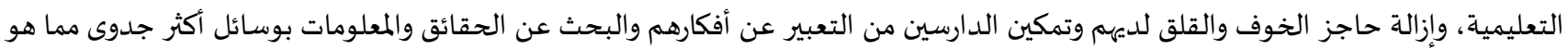

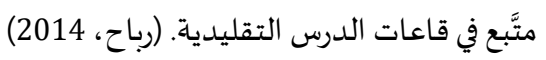

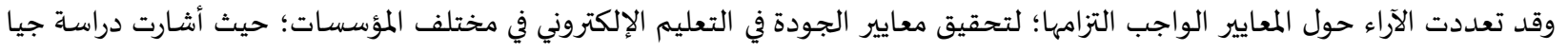

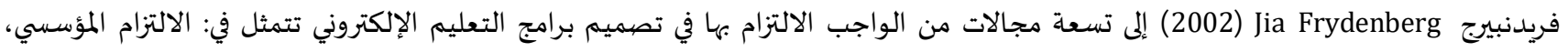
التكنولوجيا، خدمات الطلاب، تصميم التدريس وتطوير المقرر، التدريس وخدمات المعلم، توصيل البرامج، التكاليف، متطلبات الانتظام والشرعية

وبرامج التقويم (Jia Frydenberg, 2002).

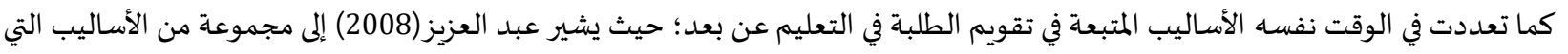

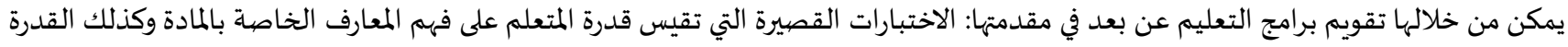

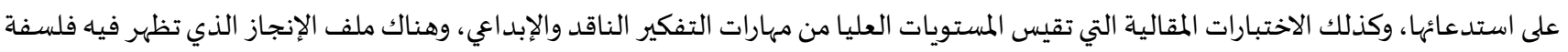

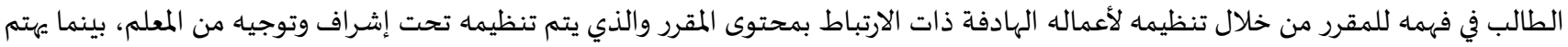

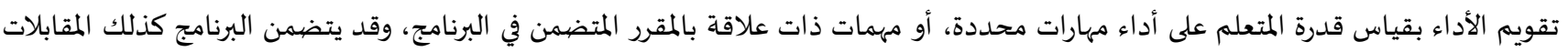

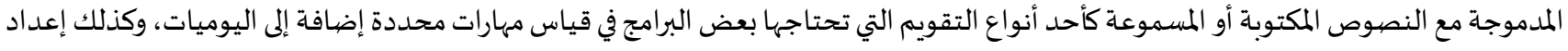

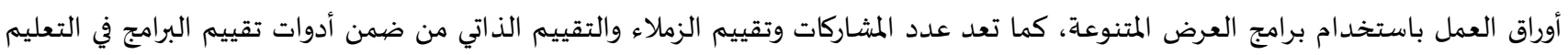
الإلكتروني المعتمدة في مثل هذه البرامج.

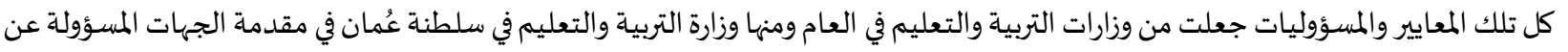

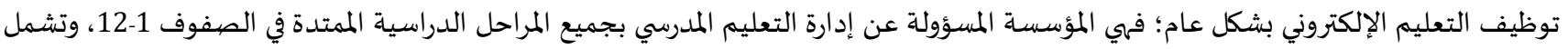

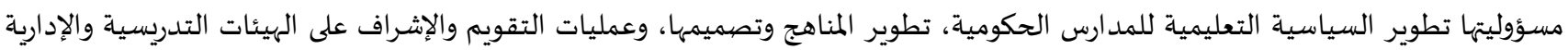

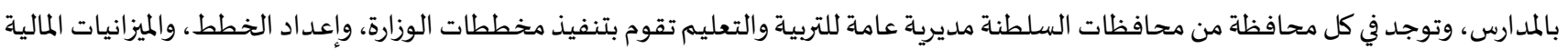

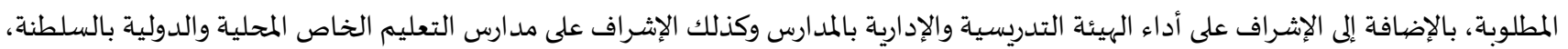

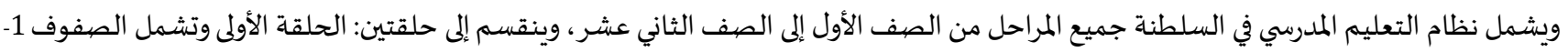

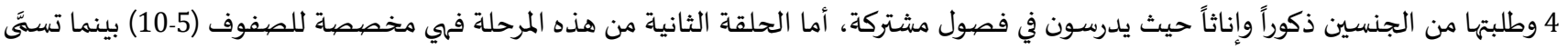

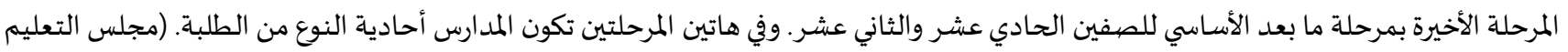

في سلطنة عُمان، 2016)

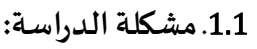

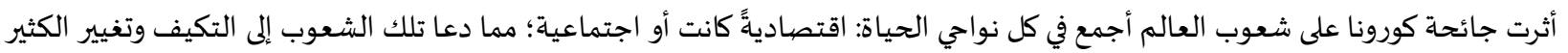

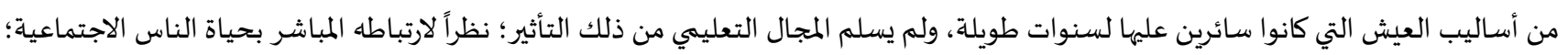

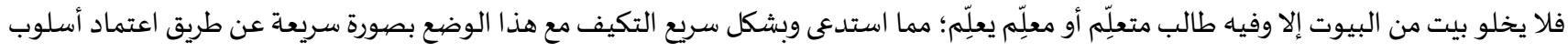

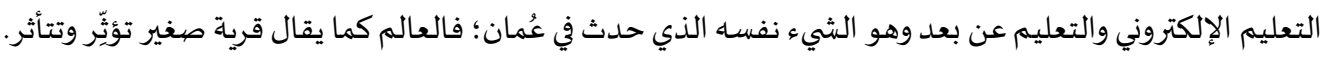

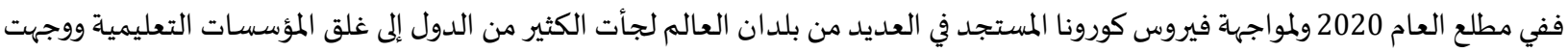

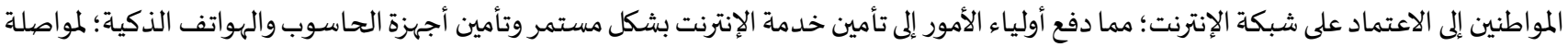

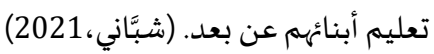


لذلك السبب فإن وزارة التربية والتعليم في سلطنة عُمان كفيرها من وزارات التربية والتعليم في دول العالم اعتمدت أسلوب التعلم عن بعد؛ لمواجهة

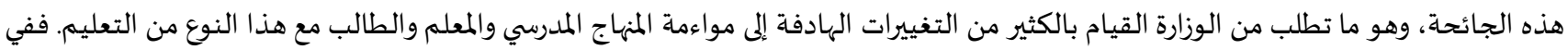

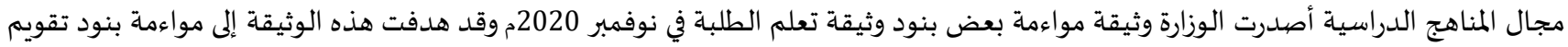

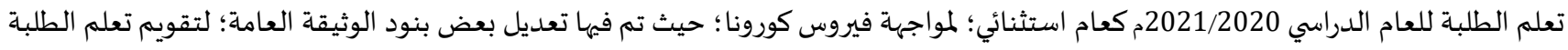
الصادرة في العام 2018؛ لتتماشى مع ظروف الجائحة، كما تم اعتماد مفهوم التعليم الإلكتروني بما فيه التعليم عن بعد والتأكيد على استثمار إمكانات

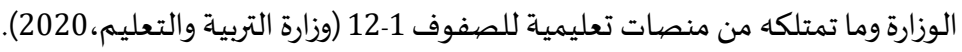

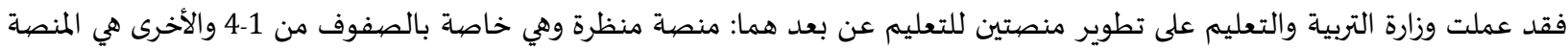

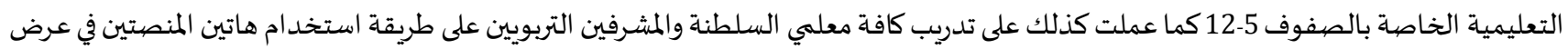
الدروس وفي تقويم الطلاب عن بعد خلال شهري سبتمبر وأكتوبر 2020م، كل تلك الجههود لم تكن بمعزل عن جهود التوعية التي قامت بها وزارة التربية

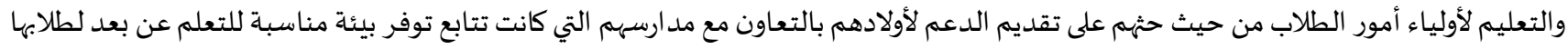

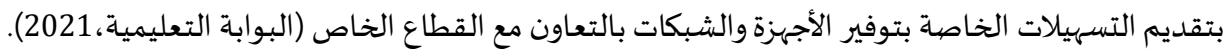
وقد عرضت السلطنة تجربتها الحالية وجهودها في توظيف التعليم عن بعد في ندوة "فقد التعليم في ظل جائحة كورونا" التي عقدتها وزارة التربية

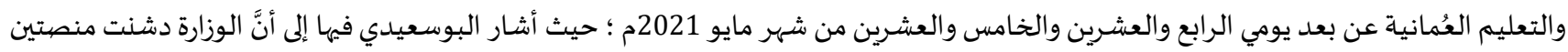

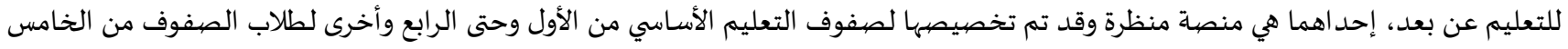

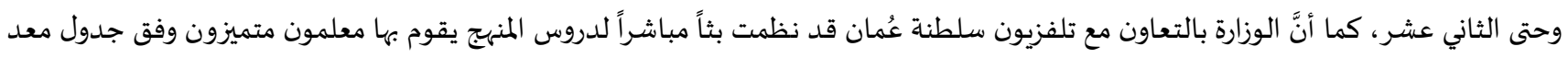
مسبقا في توقيت مناسب للطلاب وقد تم تخصيصها لطلاب الصف الثاني عشر، وللوزارة جهد كبير في تحويل المنهج في صورة إلكترونية وبثها في منصاة

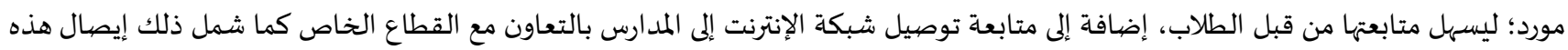

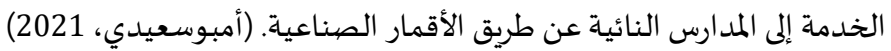

2.1. الدراسات السابقة:

وبالعودة إلى الدراسـات العُمانية في حقل التعليم الإلكتروني نجدها متنوعة قد شملت جميع أطراف العملية التعليمية فالمعنية (2016) على سبيل المثال قد درست طرفَ الإدارة المدرسية ودورها في توظيف التعليم الذي كان عاليا بحسب نتائج الدراسة وكانت مشكلة ضعف شبكات الإنترنت هي السبب الأول الذي طرحته الإدارة المدرسية كمعيق لتفعيل هذا النوع من التعليم.

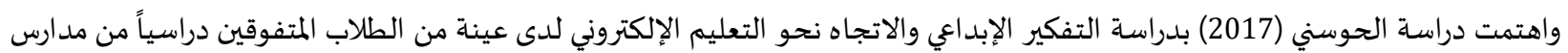
الباطنة شمال، وما يعنينا في هذه الدراسـة أهنا كشفت أنَّ اتجاهات هؤلاء الطلاب نحو التعليم الإلكتروني كانت اتجاهات إيجابية. وقد اهتمت دراسات عُمانية أخرى بمجال الكشف عن أثر التعليم الإلكتروني في التحصيل الدراسي للطلاب؛ فدراسـة الناصري (2011) قد درست

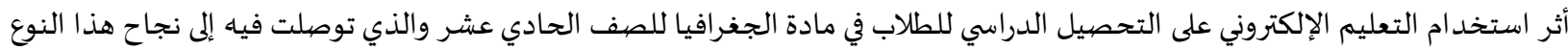

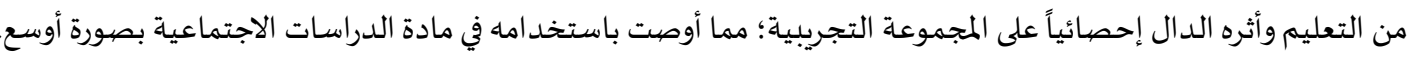

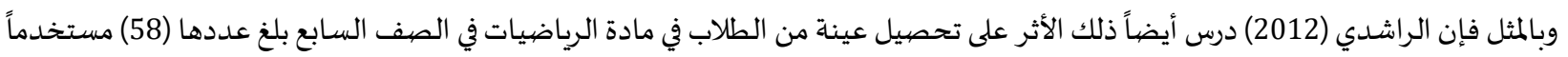

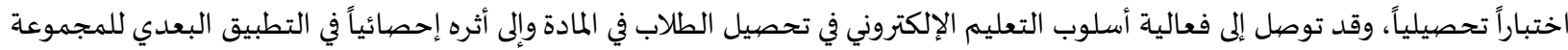
التجريبية. وأوصت دراسته بضرورة تدريب المشرفين والمعلمين على هذا النوع من التعليم من خلال إقامة الورش في مجالي تطبيقات التعليم الإلكتروني والتصيميم الإلكتروني. وتفردت دراسة الهنائي (2010) بالوقوف على الاحتياجات التدريبية في مجال التعليم الإلكتروني في مؤسسات التعليم العالي، وقد قسم تلك

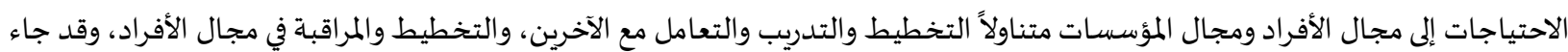

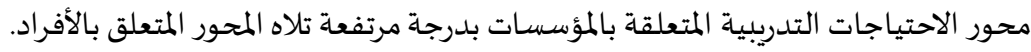

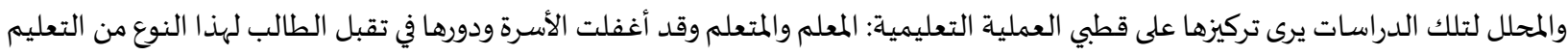
أو اتجاهات الأبوين وقناعاتهم وإمكانات تقديم المساعدة لأبنائهم؛ فهم من وجهة نظر الباحث الداعم الأول للتعليم الإلكتروني؛ لكونهم قريبين من أبنائهم

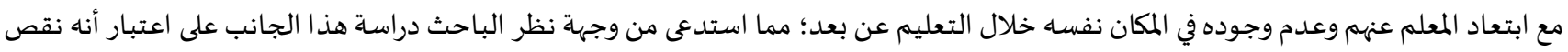

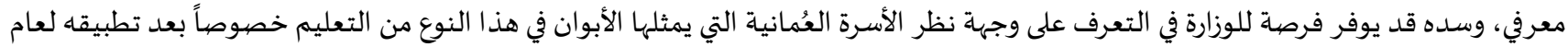
دراسي كامل خلال هذا العام 2020/ 2021م. 
الاتجاهات وقياسها:

يشير ماثيسون (2004) إلى أنَّ أغلب تعريفات الاتجاهات تركز على ثلاثة مكونات هي: تقويم الموضيوع، اتخاذ حدث تجاهاه، وبناء مشاعر تجاه ذلك الموضوع. وما يؤكد ماذهب إلياه ماثيسون مجموعة من التعريفات القديمة للاتجاهات؛ فبيك (1983، صأه5) مثلا عرَّف الاتجاهات بأنها "تقديرات سلبية

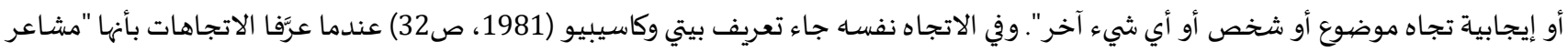

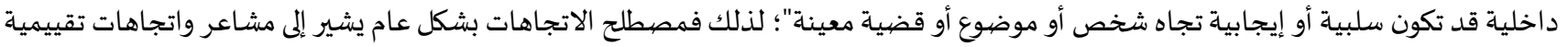

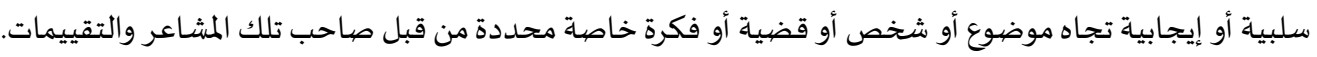

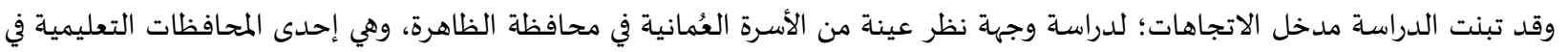

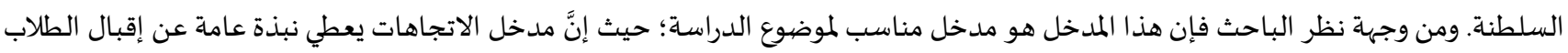

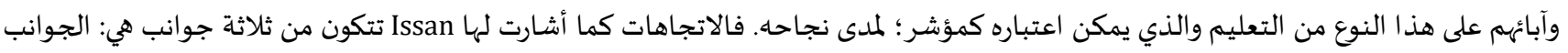
المعرفياة، جوانب التأثر والانفعال بموضوع الاتجاه، وجوانب اتخاذ موقف أو عمل تجاه هذا الاتجاه. فجوانب المعرفة تهتم بالتفكير وجمع المعلومات

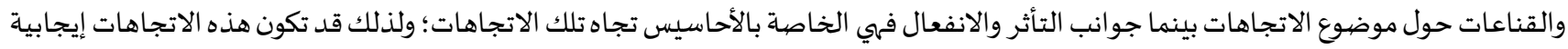
أو سلبية بينما جوانب اتخاذ الموقف فهي المختصاة بالقرارات والأعمال الناتجة عن نوع تلك الاتجاهات من قبل الشخص (Issan, 2006).

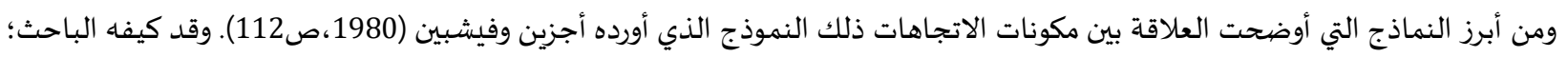

ليتناسب مع موضوع البحث الحالي كما هو واضح في الشكل التالي:

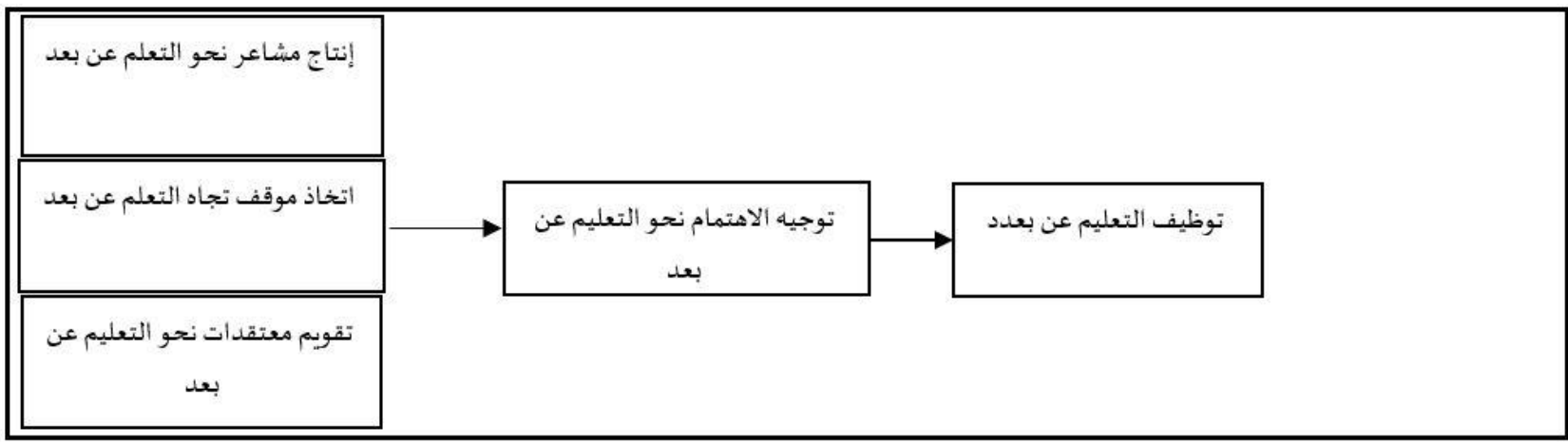

شكل (1): العلاقة بين الاتجاهات وتوظيف التعليم عن بعد لأجزين وفشبين

(Ajzen \& Fishbein, 1980, 112)

ويقوم هذا الأنموذج على أسـاس أنَّ توظيف التعليم عن بعد لا يتأثر بالسلوك مباشرة بل يتأثر بعوامل ثلاثة هي: المشاعر الداخلية، التقييمات

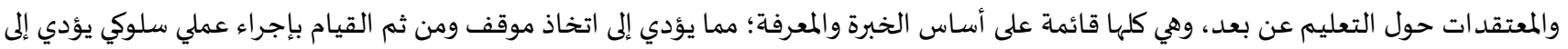
توظيف التعليم عن بعد وتبنياء. وفي نفس الاتجاه يشير أثوسن وكوفر (2004) إلى أن معظم التعريفات الخاصة بالاتجاهات قد ركزت على ثلاثة مفاهيم

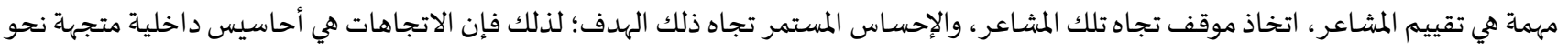
هدف من الأهد اف أو شخص أو موضوع أو فكرة مرتبطة بالقناعات الناتجة عن جمع وتلقي المعلومات؛ مما يحفز الشخص؛ لتكوين ممارسات مترابطة

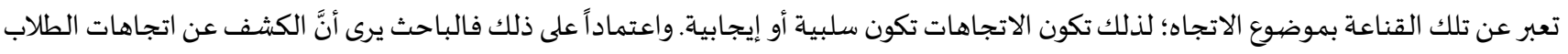
وآبائهم هو في الوقت نفساء كشف عن قناعاتهم وتفكيرهم واتجاهات مشاعرهم نحو التعليم عن بعد. أما قياس الاتجاهات عموما واتجاهات الطلاب والآباء على وجاء الخصوص فيعتمد على عدة أدوات فئهات منها الاستبانة؛ فكيربي (1986) Kerby يشير

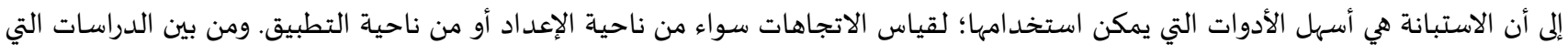
استخدمت الاستبانة دراسة (2000) AL Nasser ؛ حيث استخدمها لقياس اتجاهات عينة من المعلمات السعوديات، وكذلك دراسة الجندي (2010)

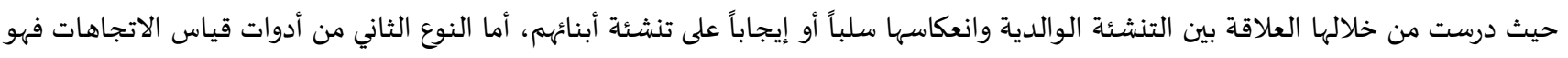

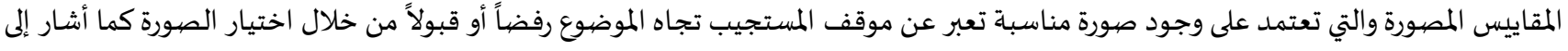

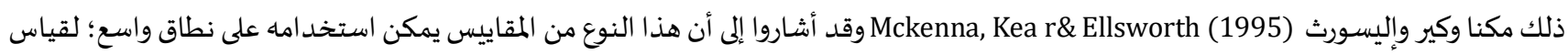
اتجاهات الأطفال في الفئات العمرية الصغيرة. والباحث هنا قد اعتمد الاستبانة؛ لقياس اتجاهات الطلاب وآبائهم نحو التعليم الإلكتروني؛ نظراً لمناسبتها

لهذه الفئة، منطلقاً من أسئلتها. 
3.1 أسئلة الدراسـة:

للدراسة الحالية سؤالان يتمثل الأول في" ما اتجاهات عينة من طلاب الصف الحادي عشر في محافظة الظاهرة وما اتجاهات آبائهم نحو التعليم عن بعد؟" أما السؤال الثاني فيتعلق بدراسة الفروق بين اتجاهات الطلاب وأبنائهم كما تعكسها استبانتا الدراسـة، ونص السؤال" هل توجد فروق بين

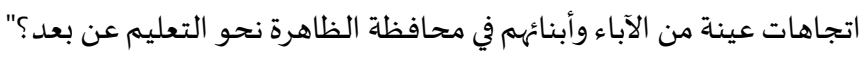

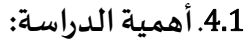

تكمن أهمية هذه الدراسـة في أهها من المتوقع أن تسـاعد وزارة التربية والتعليم في: اعتماد مقياس مقنن؛ للكشف عن واقد اقع توظيف التعليم عن بعد من وجهة نظر عينة من طلاب الصف حادي عشر وآبائهم في محافظة الظاهرة في سلطنة عُمان؛ مما من المؤمل أن يساعد المحافظة التعلئيمية في وضيع

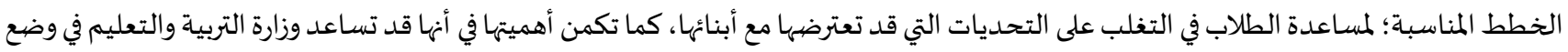
خطط مناسبة؛ لدعم اتجاهات الأسرة العُمانية نحو التعليم عن بعد؛ لتكون ثقافة مستمرة يمكن توظيفها في أية ظروف قادمة.

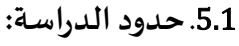
الحدود المكانية والزمانية للدراسة الحالية هي محافظة الظاهرة التعليمية للعام الدراسي 2021/2020م بينما تكمن الحدود البشرية في عينة من طلاب الصف الحادي عشر تم اختيارها بطريقة عشوائية ومعها عينة من أولياء أمورهم. بينما تكمن الحدود الموضوعية في الاتجاهات نحو توظيف

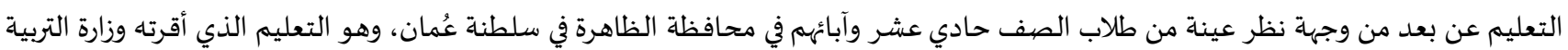
والتعليم في سلطنة عُمان من خلال المنصات التعليمياة؛ لمواجهة غلق المدارس خلاهل جانهائحة كورونا. وقد تم اعتبار إجابات الطلاب وآبائهم على المقياس هي اتجاهاتهم نحو هذا النوع من التعليم.

6.1 مصطلحات الدراسـة:

• الاتجاهات: اعتمدت الدراسة الحالية في تعريفها لهذا المصططح ما ذكرته عيسان (2006) Issan في أنَّ الاتجاهات تتكون من ثلاثة جوانب هي: المعرفة،

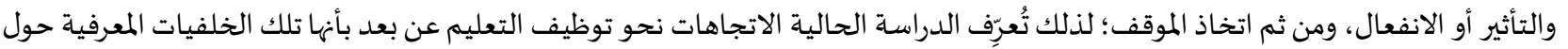
توظيف أسلوب التعليم عن بعد والذي طبقته وزارة التربية والتعليم في السلطنة في ظل جائحة كورونا كما يعكسها رأي الطلاب وآبائهم سواء كانت

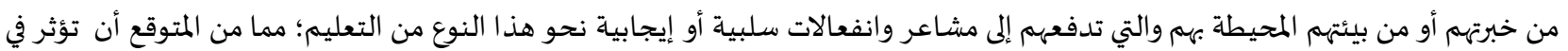
ممارساتهم المعبَّر عنها في مجموعة الفقرات الواردة في استبانتي الدراسة المقدمتين للطلاب ولآبائهم . التعليم عن بعد: هو أقرب تعريفات هذا المصطلح إلى مضمون الدراسة الحالية. ويعرِفِ شحاتة والنجار (2003) بأنه "تكنولوجيا حديثة تجتمع فيها الصيوت والصورة على وسيط واحد في شبكة الإنترنت، وهي وسائط تفاعلية ذات اتجاهين تسمح بتفاعل الدارس مع المصدر التعليمي. وقد عرفته

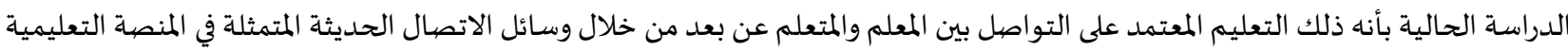
التي اعتمدتها وزارة التربية والتعليم من خلال شبكة الإنترنت.

\section{2 إجراءات الدراسـة الميدانية}

1.2. عينة الدراسـة:

ههدف التوصل إلى الخصائص السيكو مترية للاستبانتين: استبانة الطلاب واستبانة آبائهم من حيث الصددق والثبات والإجابة عن سؤالي الدراسة؛؛

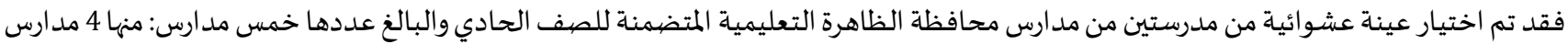

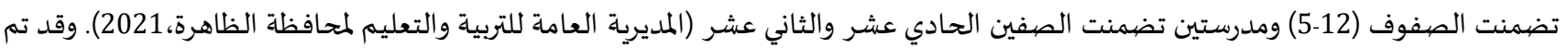
اختيار المدرستين بطريقة عشوائية عن طريق القرعة وقد بلغت تلك العينة (102) من طلاب الصف الحادي عشر؛ فهم يمثلون مرحلة التعليم العام مع طلاب الصف الثاني عشر إلا أن طلاب الصف الثاني عشر قد تم استبعادهم بسبب أنَّ الوزارة قد اعتمدت معهم أسلوب التعليم المدمج؛ نظراً لحساسية

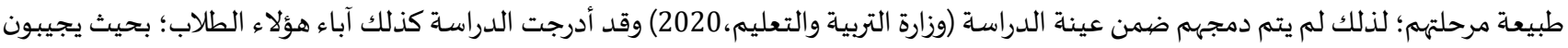
عن الفقرات الخاصة بالأبوين من قبل أحدهما ولذلك فعددهم هو مساوٍ لعدد أبنائهم (102) وبالتالي فإن المجموع الكلي لعينة الدراسة بلغ (204).

2.2 صياغة فقرات الاستبانتين:

بهدف صياغة فقرات المقياس فقد اعتمد الباحث على الدراسات التي تناولت التعليم الإلكتروني بشكل عام والتعليم عن بعد على وجه الخصيوص

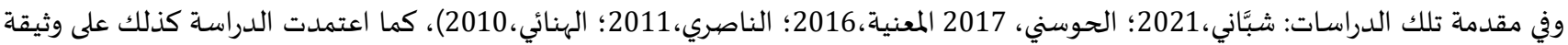

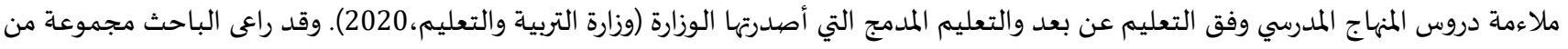
المعايير في صياغته الأولية لفقرات الاستبانتين أهمها أن تكون العبارات واضحة، قصيرة، وقليلة أيضاً؛ مراعاة لأولياء أمور الطلاب من حيث توقع فهمهم للفقرات وكذلك مراعاة لمستوى القراءة عند بعضهيهم. 
3.2. صيدق الأداتين:

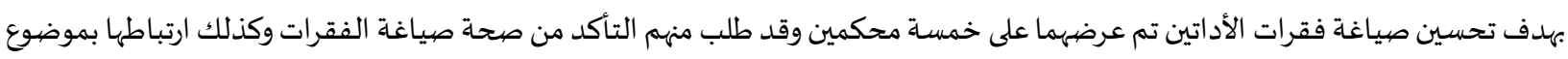
البحث إضافة إلى وضوح الفقرات لكل من الطلاب وأولياء أمورهم وقد غُيْرِت صياغة بعض الفقرات ولم تحذف أية فقرة وقد اتفق المحكمون جميعهم على ارتباط فقرات الاستبانتين بموضوع البحث. 4.2. الخصائص السيكومترية للاستبانتين: بهدف التوصل إلى الخصائص السيكومترية للاستبانتين فقد تم تطبيقهما على عينة بلغت (60) من أفراد العينة بما يساوي (30) من طلاب الصفيف الحادي عشر ومعهم أولياء أمورهم بالعدد نفسـه. وتمثلت تلك الخصائص في حساب الصدق التمييزي، صددق الاتساق الداخلي والثبات. • الصيدق التمييزي: لحسـاب الصدق التمييزي لفقرات المقياس تم حساب مجموع إجابات أفراد العينة في كل فقرة من فقرات الاستبانة ثم تصنيفها

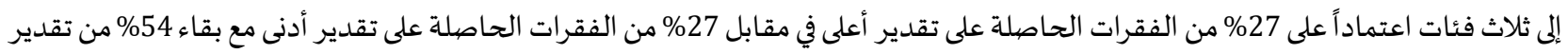
العينة في الوسط. وقد تم استخدام اختبار "ت" لحساب الفروق بين الفئتين العليا والدنيا في إجابات العينة. ويوضح الجدول الآتي نتيجة اختبار "ت"؛ لحسـاب الصيدق التمييزي لفقرات الاختبار. ويقصيد بمفهوم معامل التمييز" قدرة الفقرة على تمييز الفروق الفردية بين الأفراد الذين يعرفون

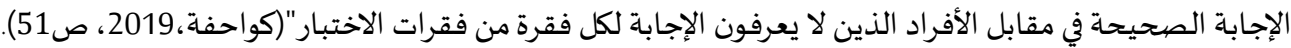

\begin{tabular}{|c|c|c|c|c|c|c|c|}
\hline مستوى & درجة & قيمة & الانحراف & المتوسط & العدد27\% & النوع & المحـور \\
\hline الدلالة & الحرية & $ت$ & المعياري & الحسابي & & الاجتماعي & \\
\hline \multirow[t]{2}{*}{.000} & 29 & -12.656 & 2.25499 & 58.5556 & 8 & الحد الأعلى & استبانة الآباء \\
\hline & & & 4.20084 & 44.3333 & 8 & الحد الأدنى & \\
\hline \multirow[t]{2}{*}{.000} & 29 & 6.624 & 2.56455 & 51.0769 & 8 & الحد الأعلى & \\
\hline & & & 4.61047 & 41.3846 & 8 & الحد الأدنى & استبانة الطلاب \\
\hline
\end{tabular}

يبين الجدول السابق وجود فروق ذات دلالة إحصائية عند مستوى دلالة (1<0.05) بين الحدين الأعلى والأدنى المتمثلين في (27\%) من الفقرات

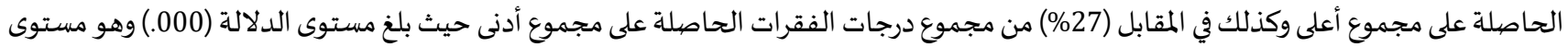

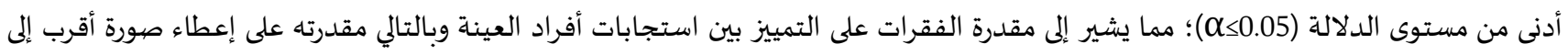
الواقع للظاهرة المقاسة. • صديدق الاتساق الداخلي: تم التوصل إلى صبدق الاتساق الداخلي بحساب معاملات ارتباط كل فقرة من فقرات المقياس مع الدرجة الكلية للمقياس كما هو موضيح في الجدول (2). جدول (2): نتائج معامل ارتباط كل فقرة من فقرات استبانتي الآباء والأبناء مع الدرجة الكلية للمقياس

\begin{tabular}{|c|c|c|c|c|c|}
\hline \multirow{3}{*}{ مستوى الدلالة } & \multicolumn{3}{|l|}{ استبانة الأبناء } & \multirow{3}{*}{ معامل الارتباط الآباء } & \multirow{3}{*}{ رقم الفقرة } \\
\hline & معامل الارتباط & رقم الفقرة & مستوى & & \\
\hline & & & الدلالة & & \\
\hline .004 & .745 & 1 & .000 & $.710^{*}$ & 1 \\
\hline .000 & .778 & 2 & .000 & 0.771 & 2 \\
\hline .001 & .794 & 3 & .002 & $.739^{*}$ & 3 \\
\hline .015 & .775 & 4 & .042 & $.759 *$ & 4 \\
\hline .000 & .760 & 5 & .000 & $.724^{*}$ & 5 \\
\hline .007 & .703 & 6 & .002 & $.775^{*}$ & 6 \\
\hline .000 & .762 & 7 & .000 & $.714^{*}$ & 7 \\
\hline .000 & .782 & 8 & .000 & $.781^{*}$ & 8 \\
\hline .006 & .777 & 9 & .005 & $.743^{*}$ & 9 \\
\hline .001 & .756 & 10 & .001 & $.711^{*}$ & 10 \\
\hline .005 & .734 & 11 & .000 & $.787^{*}$ & 11 \\
\hline .000 & .787 & 12 & .003 & $.718^{*}$ & 12 \\
\hline .000 & .739 & 13 & .004 & $.769^{*}$ & 13 \\
\hline .003 & .755 & 14 & .000 & $.766^{*}$ & 14 \\
\hline .000 & 743. & 15 & .000 & $.741^{*}$ & 15 \\
\hline
\end{tabular}

وتظهر نتائج معامل الاتساق الداخلي في الجدول السـابق أن معاملات الاتساق الداخلي بين المجموع الكلي لاستبانة الآباء مع كل فقرة من فقراتها

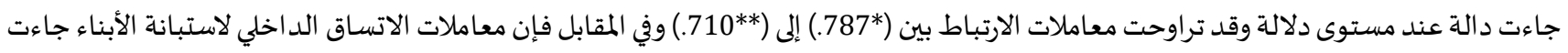

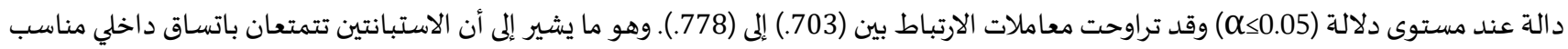
يجعلهما صالحتين؛ للتطبيق. ثبات المقياس: تم استخراج ثبات فقرات المقياس باستخدام معامل الثبات ألفا لكرونباخ؛ وذلك بحساب ثبات كل فقرة على حدة مع حساب الثبات

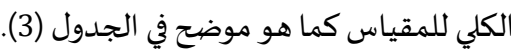


جدول (3): قيم معامل ألفا لكرونباخ لكل فقرة من استبانتي الآباء والأبناء مع الدرجة الكلية لكل منهما

\begin{tabular}{|c|c|c|c|}
\hline \multicolumn{2}{|c|}{ استبانة الأبناء } & \multicolumn{2}{|c|}{ استبانة الآباء } \\
\hline قيم معامل ألفا لكرونباخ & رقم الفقرة & قيم معامل ألفا لكرونباخ & رقم الفقرة \\
\hline .777 & 1 & .763 & 1 \\
\hline .735 & 2 & .765 & 2 \\
\hline .767 & 3 & .795 & 3 \\
\hline .732 & 4 & .754 & 4 \\
\hline .716 & 5 & .748 & 5 \\
\hline .730 & 6 & .766 & 6 \\
\hline .721 & 7 & .761 & 7 \\
\hline .741 & 8 & .749 & 8 \\
\hline .735 & 9 & .756 & 9 \\
\hline .717 & 10 & .773 & 10 \\
\hline .713 & 11 & .709 & 11 \\
\hline .794 & 12 & .701 & 12 \\
\hline .763 & 13 & .755 & 13 \\
\hline .780 & 14 & .773 & 14 \\
\hline .777 & 15 & .757 & 15 \\
\hline
\end{tabular}

يتضح من نتائج الجدول السـابق أن قيم معامل الثبات لفقرات استبانة الآباء قد تراوحت بين (749.) و (756.) وفي المقابل بينت النتائج أنَّ قيم

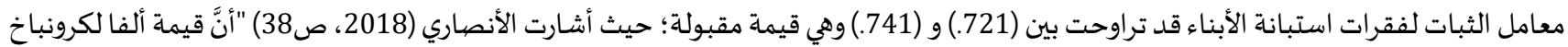
يجب أن لاتقل عن 0.70 "

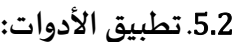

بهدف تطبيق أداتي الدراسة؛؛ لجمع البيانات تم اختيار مدرستين من مد ارس محافظة الظاهرة المتضمنة للصف الحادي عشر والبالغ عددها خمس

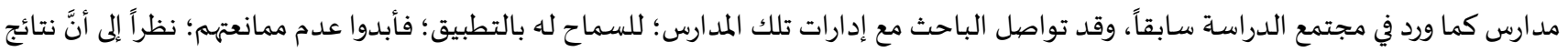
الدراسة ستشكل أهمية في عملهم. وقد تم التطبيق ورقياً باختيار صفين من كل مدرسة بطريقة عشورائية أيضاً بحيث يجيب الطالب على الاستبانة

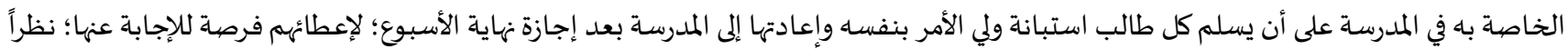

لوجود البعض منهم في عمل خارج محافظة الظاهرة.

\section{3. عرض النتائج ومناقشتها}

بهدف الحكم على مستوى اتجاهات الطلاب عينة الدراسة وأولياء أمورهم نحو التعليم عن بعد تم استخد ام معيار الحكم الآتي كما أورده كرونسك (Krosnick, 1999, 50)؛ لقياس الاتجاهات وهو عبارة عن مقياس ليكرت يمتد من درجاة إلى خمس أو سبع درجات بحيث تمثل الدرجتان الأولى والثانية

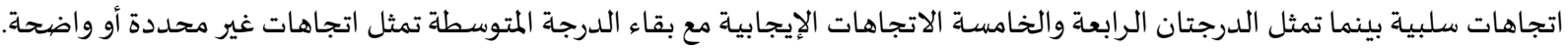
جدول (4): معيار الحكم على قوة الآراء و اتجاهها بحسب تصنيف (Krosnick, 1999, 50)

\begin{tabular}{|c|c|c|}
\hline اتجاه الرأي & مستوى / قوة / المو افقة على الرأي & المتوسط الحسابي \\
\hline سلبي & بدرجة قليلة جداً & $1.49-1$ \\
\hline سلبي & بدرجة قليلة & $2.49-1.50$ \\
\hline- & 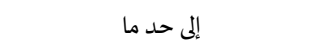 & $3.49-2.50$ \\
\hline إيجابي & بدرجة عالية & $4.49-3.50$ \\
\hline إيجابي & بدرجة عالية جداً & 5.0-4.50 \\
\hline
\end{tabular}

1.3. السؤال الأول من أسئلة الدراسة والذي نص على" ما و اقع توظيف التعليم عن بعد من وجهة نظرعينة من طلاب الصفف حادي عشرو آبائهم

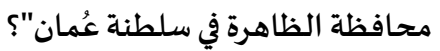
ولإجابة عن السؤال تم استخدام المتوسطات الحسابية والانحرافات المعيارية؛ لتحديد مستوى تلك الآراء واتجاهها اعتماداً على معيار التفسير

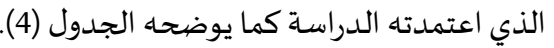

جدول (5): آراء الأسرة العُمانية " ط= الطلاب / و= أولياء أمورهم" في محافظة الظاهرة نحو التعليم عن بعد

\begin{tabular}{|c|c|c|c|c|}
\hline 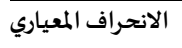 & المتوسط الحسابي & العبـارة & ط/و & \\
\hline 1.071 & 3.94 & بالنسبة لي كولي أمر استطعت أن أتأقلم مع تعليم أبنائي عن بعد. & 9 & 1 \\
\hline 1.143 & 3.88 & بالنسبة لي كطالب استطعت التأقلم مع التعلم عن بعد. & b & \\
\hline .898 & 4.26 & التعلم عن بعد كان مفيدا لأبنائي بشكل عام في تعلم مهارات لها علاقة باستخدام التقانة. والتكنولوجيا. & 9 & 2 \\
\hline 1.190 & 3.85 & التعلم عن بعد كان مفيدا لي في تعلم مهارات لها علاقة باستخدام التقانة والتكنولوجيا. & b & \\
\hline 1.142 & 3.29 & أظن أنًّ أبنائي فهموا دروسهم عن طريق التعلم عن بعد بصورة مساوية للتعلم المباشر في المدرسة. & 9 & 3 \\
\hline 1.038 & 3.04 & فهمت دروسي عن طريق التعلم عن بعد بصورة مساوية للتعلم المباشر في المدرسة. . & b & \\
\hline 1.200 & 2.88 & في رأيي إن بعض دروس في المواد المختلفة لا يصلح تعلمها عن بعد. & 9 & 4 \\
\hline .919 & 2.27 & في رأيي نظام التعليم عن بعد يصلح لبعض المواد دون غيرها & b & \\
\hline
\end{tabular}




\begin{tabular}{|c|c|c|c|c|}
\hline 1.250 & 3.88 & التعلم عن بعد كان ممتعا لأبنائي. & 9 & 5 \\
\hline .999 & 2.96 & التعلم عن بعد كان ممتعا. & b & \\
\hline 1.237 & 2.53 & مشكلتي في التعلم عن بعد يكمن في مهارات استخدام الحاسوب عند بعض أبنائي. & 9 & 6 \\
\hline 1.065 & 2.42 & مشكلتي في التعلم عن بعد يكمن في مهارات استخدام الحاسوب. م & b & \\
\hline 1.493 & 2.79 & أبنائي أحبوا التعلم عن يعد ولكنهم يواجهون مشكلة في استخدام المنصة. & و & 7 \\
\hline 1.107 & 4.23 & أحب التعلم عن يعد ولكني أواجه مشكلة في استخدام المنصة. & b & \\
\hline 1.478 & 2.76 & الشبكة وقوة الإنترنت هي العائق الوحيد الذي كان قد واجهنا كعائلة في تعليم طلابنا عن بعد. & 9 & 8 \\
\hline 1.208 & 2.46 & الشبكة وقوة الإنترنت هي العائق الوحيد الذي كان يواجهن. & b & \\
\hline 1.149 & 4.12 & كعائلة كنا نساعد أبنائنا بشكل عام خلال الدروس المباشرة وغير المباشرة في المنصة. & 9 & 9 \\
\hline 1.287 & 2.15 & كانت عائلتي متعاونة معي في توفير ما أحتاجه خلال التعلم عن بعد. & b & \\
\hline .968 & 4.18 & من وجهة نظري طريقة الاختبارات من خلال المنصة كانت طريقة محبوبة عند أبنائي. & 9 & 10 \\
\hline 1.451 & 3.12 & طريقة الاختبارات القصيرة من خلال المنصية كانت طريقة سهلة وواضحة. & b & \\
\hline 1.008 & 3.88 & 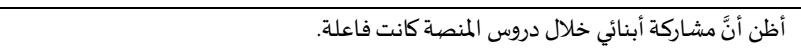 & 9 & 11 \\
\hline .809 & 4.58 & 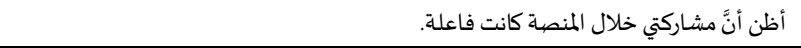 & b & \\
\hline 1.015 & 3.62 & كنت أهتم بمتابعة دروس أبنائي في أسبوع التعليم غير المباشر. & 9 & 12 \\
\hline .761 & 4.46 & كنت أهتم بدروسي في أسبوع التعليم غير المباشر. & b & \\
\hline 1.015 & 4.00 & أنا على قناعة أنَّ أبنائي أدوا واجباتهم في أسبوع التعلم غير المباشر بانتظام. & 9 & 13 \\
\hline .895 & 4.19 & أؤدي واجباتي في أسبوع التعلم غير المباشر. . & b & \\
\hline .40010 & 3.4554 & المتوسط العام & & \\
\hline
\end{tabular}

وبالعودة إلى جدول (5) يتضح أن المتوسط الحسابي الدال على مستوى آراء الآباء العُمانيين في محافظة الظاهرة نحو توظيف التعليم عن بعد العدا

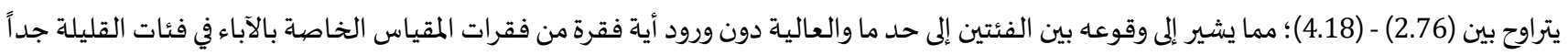

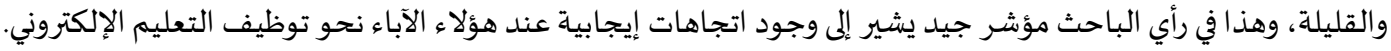

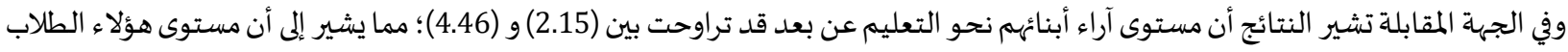

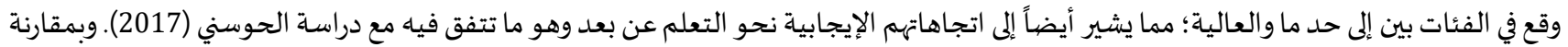

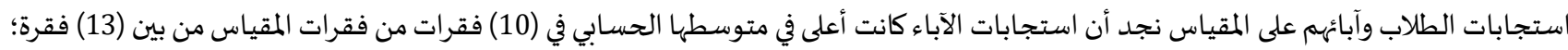

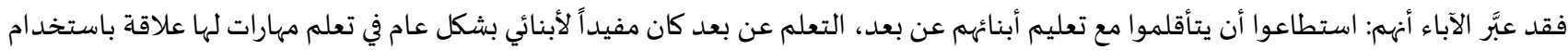

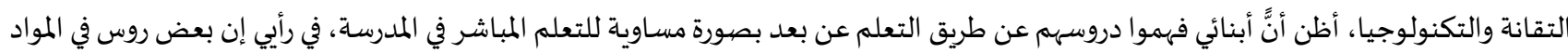

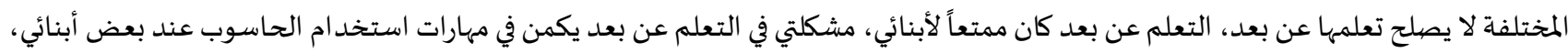

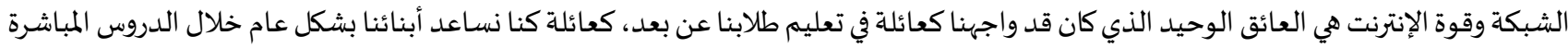

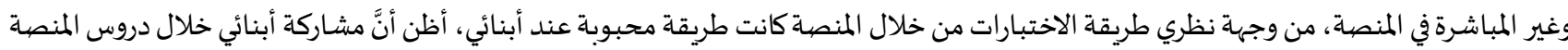
كانت فاعلة.

هذه النتيجة أيضاً وضحت أنَّ هناك تقارباً واتفاقاً بين آراء الطلاب وآبائهم في بعض جوانب المقياس من مثل: أنَّ ولي الأمر والطالب في محافظة

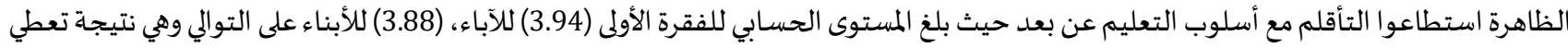

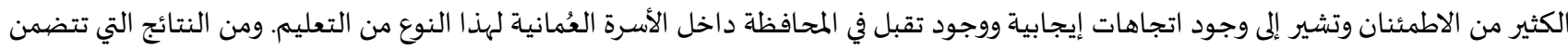

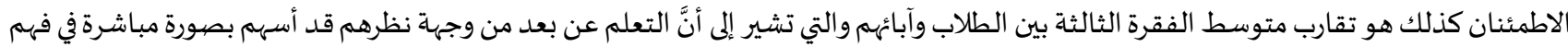

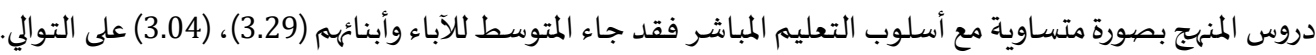

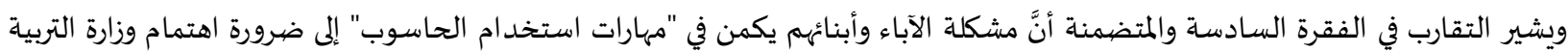

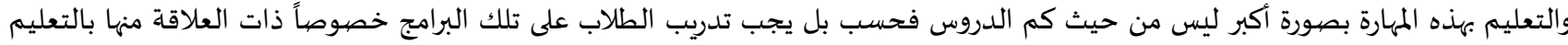
الإلكتروني والتواصل الإلكتروني والتعليم عن بعد وألا كما يجب أن ذلك التدريب على الطلاب؛ فالواقع يشير إلى ضرورة تعريف الآباء أيضاً على تلك الك الكالي

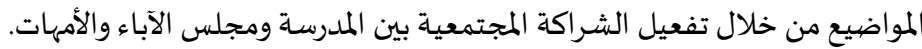

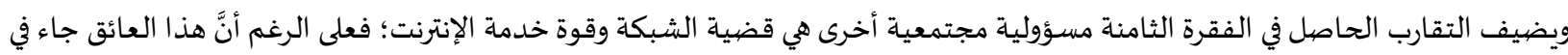

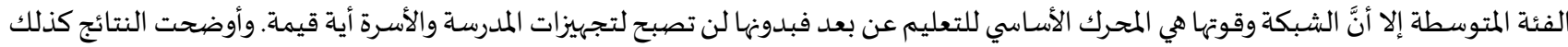

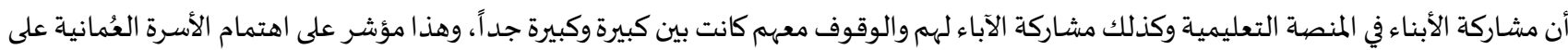

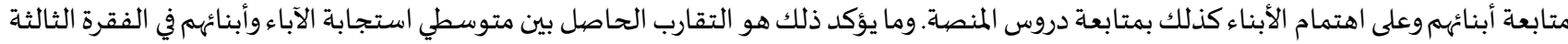

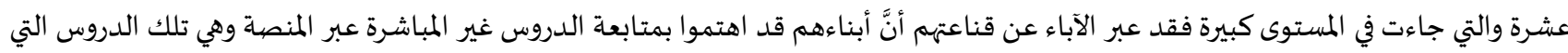


تعتمد على التعلم الذاتي من قبل الطلاب دون وجود تفاعل مباشر بين المعلمين وطلابهم عن طريق برنامج جوجل ميت، وهو ما اتفق فيه الطلاب أيضاً؛ حيث عبروا عن قيامهم بواجباتهم الخاصة بالدروس غير المباشرة عبر المنصية وأههم لم يهملوها. وفي المقابل فإن الطلاب قد عبروا عن اتجاهاتهم نحو التعليم عن بعد بمتوسط حسابي أكبر من آبائهم في ثلاث فقرات من بين 13 تضمنها المقياس

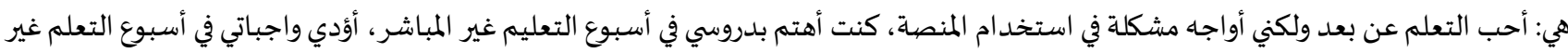
المباشر. وقد تكون نتيجة ارتفاع المتوسط الحسابي في هذه الفقرات؛ نتيجة التماس المباشر بين الطلاب وتوظيف المنصاة في مقابل الآباء الذين تتمثل

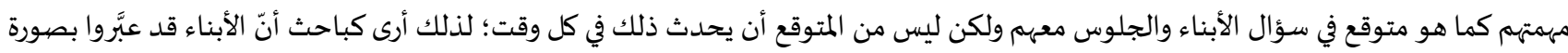
أكثر واقعية مقارنة بآبائهم.

2.3. السؤال الثاني: للإجابة عن السؤال الثاني من أسئلة الدراسـة والذين نص على" هل توجد فروق ذات دلالة إحصائية بين وجهة نظر الطلاب

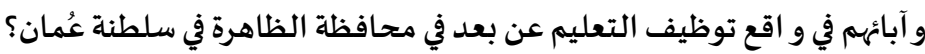
للإجابة عن السؤال تم استخدام اختبار "ت لمجمموعتين مستقلتين Independent T Test؛ للكشف عن تلك الفروق كما هو واضح من الجدول الآتي.

\begin{tabular}{|c|c|c|c|c|c|c|c|}
\hline مستوى & درجة & قيمة & الانحراف & المتوسط & العدد & النوع الاجتماعي & المحسور \\
\hline الدلالة & الحرية & $ت$ & المعياري & الحسابي & & & \\
\hline \multirow[t]{2}{*}{.767} & 58 & 298 & .42047 & 3.4308 & 26 & الطلاب & اتجاهات الأسرة \\
\hline & & & .40633 & 3.4627 & 34 & الآباء & \\
\hline
\end{tabular}

ويشير الجدول السابق إلى عدم وجود فروق ذات دلالة إحصائية بين وجهة نظر الطلاب وآبائهم نحو توظيف التعليم عن بعد في محافظة الظاهرة؛

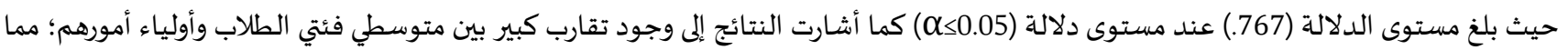
يشير إلى أنَّ الأسرة العُمانية تتفق فيما بينها على وجود اتجاهات إيجابية نحو التعليم عن بعد؛ حيث بلغ المتوسط الحسابي العام للطلاب (3.4308)

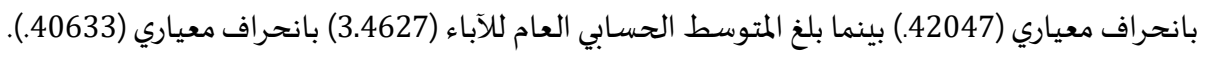

بما أن النتائج قد أظهرت وجود اتجاهات إيجابية نحو التعليم عن بعد عن الطلاب وآبائهم على حد سواء فإن الدراسـة توصي وزارة التربية والتعليم بتعزيز تلك الاتجاهات من خلال برامجها وأنشطتها المتنوعة ومن خلال الشراكة المجتمعية مع المجتمع بالتعاون مع مجالس الآباء والأمهات في كل مدرسة، ونظرا لاتفاق الآباء وأبنائهم في وجود تحديات تقنية مشتركة في مهارات استخدام الحاسوب والتعامل مع شبكة الإنترنت؛ فالدراسة توصي المحافظة

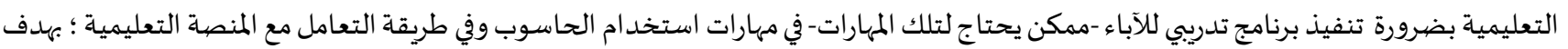
مساعدتهم في تقديم الدعم لأبنائهم في البيت

4.3 مقترحات ببحوث أخرى:

تقترح الدراسة دراسة اتجاهات طلاب التعليم الأساسي نحو التعليم عن بعد للصفوف (5-10) ومقارنها مع اتجاهات آبائه، كما تقترح الدراسة كذلك دراسة علاقة اتجاهات الوالدين وأبنائهم نحو التعليم عن بعد بمتغيرات متنوعة مهمة كالمستوى التعليمي للآباء والنوع الاجتماعي للأبناء.

1. أمبوسعيدي، عبدالله بن خميس (2021). ندوة الفاقد التعليهي في ظل جائحة كورونا. وزارة التربية والتعليم - مسقط- 25-24 مايو.

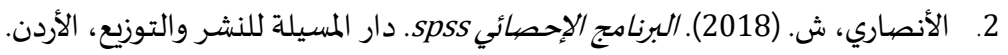

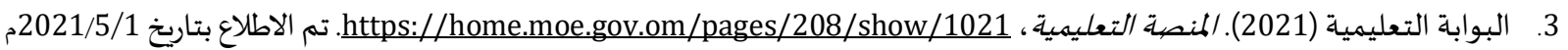
4. حمدي أحمد عبد العزيز وحمدي أحمد (2008). التعليم الإلكتروني، الفلسفة - المبادئ- الأدوات - التطبيقات. عُمان، دار الفكر للنشر والتوزيع.

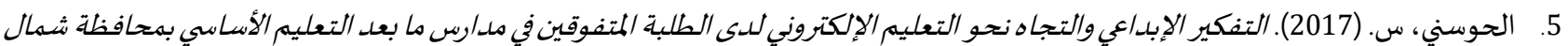
الباطنة. (رسالة ماجستير غير منشورة) جامعة نزوى. (الخفي

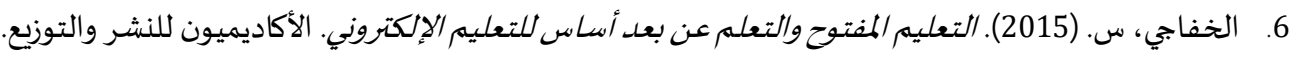
7. الراشـدي، علي بن ناصر (2012). أثر التعليم الإلكتروني للرياضيات على تحصيل الصيف السابع الأساسي في سلطنة عُمان ودافعيتهم نحو تعلم الرياضيات. (رسالة ماجستير غير منشورة) جامعة السلطان قابوس. لرسئ. 
8. رباح، م. (2014). التعليم الإككتروني. الأردن: دار المناهج. :- ISBN 978-9957-18-019-3 retrivedd on 10/5/2021. تم الاطلاع بتاريخ

9 9. شباني، س. (2014). تحديات التعلم عن بعد مقاربة لاثني عشر بحثا عربيا في مخاطر الإدمان على الإنترنت "دراسة وصفية تحليلية". مجللة الحداثة.

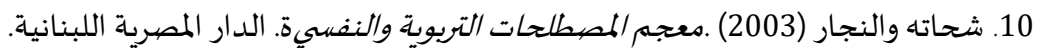

11. شلوسر، لي آرشر و سيمونسن، مايكل (2015). التعليمر عن بعلد ومصرطلحات التعليم الإلكتروني. ترجمة: نبيل جاد عزمي. مكتبة بيروت.

12. كوافحة، ت. (2010). القياس والتقويم وأساليب القياس والتشخيص في التوبية الخاصة. دار المسيرة، الأردن.

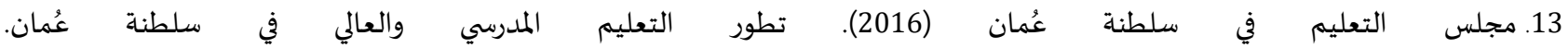
2021/4/28 http://www.educouncil.gov.om/page.php?scrollto=start\&id=15,Retrived,on 6/5/2021

14. المديرية العامة للتربية والتعليم لمحافظة الظاهرة (2021). الإحصاءات التويوية. قسم الإحصياء والخربطة المدرسية بمحافظة الظاهرة.

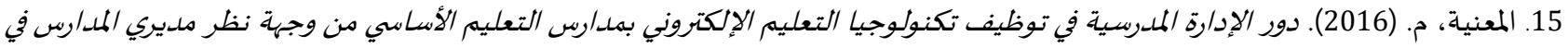

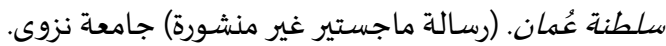

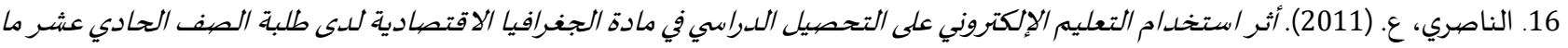

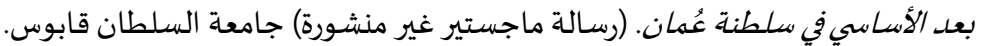

17. الهنائي، س. (2010). الاحتياجات اللازمة لإدارة التعليم الإلكتروني في مؤسسات التعليم العالي في سلطنة عُمان. (رسالة ماجستير غير منشورة)،

جامعة السلطان قابوس.

18. وزارة التربية والتعليم (2020). وثيقة مواءمة بعض بنود تقوبيمتعلم الطلبة في مادة اللغة العببية للصفوف (5-12)، مركز القياس والتقويم التربوي. سلطنة عُمان.

ثانياً: المراجع الأجنبية:

1. Ajzen, I \& Fishbein, M. (1980). Understanding attitudes and predicting social behavior. New Jersey: Prentice-Hall press.

2. Issan, S. (2006). Aims and instructional, behavioral objectives their classification. AL Kuwait: Falah Publishing Library

3. Jia Frydenberg (2002). Quality Standards in E-Learning: A matrix of analysis, International Review of Research in Oper and Distance Learning, 3(2). https://doi.org/10.19173/irrodl.v3i2.109

4. Kerby, M. (1986). Assessing student attitudes toward reading. School Library Journal, 33 (4): 43.

5. Krosnick, J. (1999). Maximizing questionnaire quality. In J. Robinson, P. Shaver, \& L. Wrightsman (Eds.), Measures of Political Attitudes (pp. 50-69). New York, NY: Academic Press.

6. Mathewson \& Grover. (2004). Model of attitude influence upon reading and learning to read, theoretical models and processes of reading (5th ed). USA: International Reading Association. PP.1431-1461

7. Mathewson \& Grover. (2004). Model of attitude influence upon reading and learning to read, in Ruddell, $R$ and Unrau. Theoretical models and processes of reading (5th ed). USA: International Reading Association. PP.1431-1461.

8. McKenna, Kear \& Ellsworth. (1995). Children's attitudes toward reading: a national survey. Journal of Reading Research Quarterly, 30(4): 934-956. https://doi.org/10.2307/748205

9. AL Nasser, S. (2000). The attitudes towards reading and teaching reading in content area of secondary school in the kingdom of Saudi Arabia. Available from ProQuest Dissertations and Theses database. (UMI N0. 9985826). 
المجلة الدولية للدراسات التربوية والنفسية

PU 100

www.refaad.com
International Journal of Educational \& Psychological Studies (EPS)

Journal Homepage: https://www.refaad.com/views/EPSR/Home.aspx

ISSN: 2520-4149 (Online) 2520-4130 (Print)

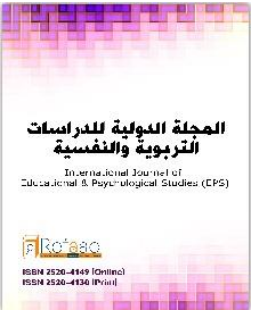

\title{
Reality of implementation the learning distance from the viewpoint of 11 grade students and their parents selected randomly from Aldahirah governate under the Corona pandemic
}

\author{
Saif Nasser Saif Alazri \\ Assistant professor, college of since and Arts, Nizwa University, KSA \\ saifnasser@unizwa.edu.om
}

Received : 11/5/2021 Revised : 23/5/2021 Accepted : 9/6/2021 DOI : https://doi.org/10.31559/EPS2021.10.2.6

\begin{abstract}
This study aimed to uncover the reality of implementation the learning distance from the viewpoint of 11 grade students and their parents selected randomly from Aldahirah governate. Two Questionnaires were used to collect the data and a sample of (104) students and their parents were participated in this study. The results revealed that both students and parents have positive attitudes toward implementation the distance learning, both point view of students and their parents ranged from medium to strong and reflected positive attitudes toward distance learning. Parents point view were more positive than students in (12) statements out of (15), and there was compatibility between parents and their children in some statement of the Questionnaires such as, students and their parents have been adjusting with distance learning, distance learning supported comprehensive subjects with the same power of direct learning and providing the internet service was the first challenge faced Omani families. The study ended with some recommendations.
\end{abstract}

Keywords: learning distance; basic education; sultanate of Oman.

\section{References:}

1. Ambws'ydy, 'bdallh Bn Khmys (2021). Ndwt Alfaqd Alt'lymy Fy Zl Ja'ht Kwrwna. Wzarh Altrbyh Walt'lym - Msqt- 24-25 Mayw.

2. Alansary, Sh. (2018). Albrnamj Alehsa'y Spss. Dar Almsylh Llnshr Waltwzy', Alardn.

3. Albwabh Alt'lymyh (2021). Almnsh Alt'lymyh, https://home.moe.gov.om/pages/208/show/1021. tm alatla'e btarykh 1/5/2021m

4. Hmdy Ahmd 'bd Al'zyz Whmdy Ahmd (2008). Alt'lym Alelktrwny, Alflsfh - Almbad'- Aladwat - Alttbyqat. 'uman, Dar Alfkr Llnshr Waltwzy'.

5. Alhna'y, S. (2010). Alahtyajat Allazmh Ledart Alt'lym Alelktrwny Fy M'ssat Alt'lym Al'aly Fy Sltnt 'uman. (Rsalt Majstyr Ghyr Mnshwrh), Jam't Alsltan Qabws.

6. Alhwsny, S. (2017). Altfkyr Alebda'y Waltjah Nhw Alt'elym Alelktrwny Lda Altlbh Almtfwqyn Fy Mdars Ma B'd Alt'lym Alasasy Bmhafzt Shmal Albatnh. (Rsalt Majstyr Ghyr Mnshwrh) Jam't Nzwa.

7. Alkhfajy, S. (2015). Alt'lym Almftwh Walt'lm 'n B'd Asas Llt'lym Alelktrwny. Alakadymywn Llnshr Waltwzy'.

8. Kwafhh, T. (2010). Alqyas Waltqwym Wasalyb Alqyas Waltshkhys Fy Altrbyh Alkhash. Dar Almsyrh, Alardn.

9. Alm'nyh, M. (2016). Dwr Aledarh Almdrsyh Fy Twzyf Tknwlwjya Alt'lym Alelktrwny Bmdars Alt'lym Alasasy Mn Wjht Nzr Mdyry Almdars Fy Sltnt 'uman. (Rsalt Majstyr Ghyr Mnshwrh) Jam't Nzwa.

10. Almdyryh Al'amh Lltrbyh Walt'lym Lmhafzh Alzahrh (2021). Alehsa'at Altrbwyh. Qsm Alehsa' Walkhryth Almdrsyh Bmhafzt Alzahrh.

11. Mjls Alt'lym Fy Sltnt 'uman (2016). Ttwr Alt'lym Almdrsy Wal'aly Fy Sltnt 'uman. http://www.educouncil.gov.om/page.php?scrollto=start\&id=15,retrived,0n 6/5/2021. Tm Alatla' Btarykh 28/4/2021m

12. Alnasry, '. (2011). Athr Astkhdam Alt'lym Alelktrwny 'la Althsyl Aldrasy Fy Madh Aljghrafya Alaqtsadyh Lda Tlbt Alsf Alhady 'shr Ma B'd Alasasy Fy Sltnt 'uman. (Rsalt Majstyr Ghyr Mnshwrh) Jam't Alsltan Qabws.

13. Alrashdy, 'ly Bn Nasr (2012). Athr Alt'lym Alelktrwny Llryadyat 'la Thsyl Alsf Alsab' Alasasy Fy Sltnh 'uman Wdaf'ythm Nhw T'Im Alryadyat. (Rsat Majstyr Ghyr Mnshwrh) Jam't Alsltan Qabws.. 
14. Rbah, M. (2014). Alt'lym Alelktrwny. Alardn: Dar Almnahj. : Retrivedd On 10/5/2021 Isbn 978-9957-18-019-3. Tm Alatla' Btarykh 20/5/2021m

15. Shbany, S. (2014). Thdyat Alt'lm 'n B'd Mqarbh Lathny 'shr Bhtha 'rbya Fy Mkhatr Aledman 'la Alentrnt "Drash Wsfyh Thlylyh". Mjlt Alhdathh.

16. Shhath Walnjar (2003). M'jm Almstlhat Altrbwyh Walnfsyh. Aldar Almsryh Allbnanyh.

17. Shlwsr, Ly Arshr W Symwnsn, Maykl (2015). Alt'lym 'n B'd Wmstlhat Alt'lym Alelktrwny. Trjmt: Nbyl Jad 'zmy. Mktbt Byrwt.

18. Wzart Altrbyh Walt'lym (2020). Wthyqt Mwa'mt B'd Bnwd Tqwym T'lm Altlbh Fy Madt Allghh Al'rbyh Llsfwf (5-12), Mrkz Alqyas Waltqwym Altrbwy. Sltnt 'uman. 